\title{
Pengaruh Terapi Guided Imagery Terhadap Nyeri Pada Pasien Post Operasi Fraktur Di Ruang Bougenvil RSUD Dr. R. Koesma Tuban
}

\author{
Novia Dwi Astuti ${ }^{1}$, Conventie Ari Respati ${ }^{2}$ \\ ${ }^{1}$ Program Studi D III Kebidanan STIKES Nahdlatul Ulama Tuban \\ ${ }^{2}$ Program Studi D III Kebidanan STIKES Nahdlatul Ulama Tuban \\ Email : noviastikesnu@gmail.com
}

\begin{abstract}
ABSTRAK
Nyeri pada pasien fraktur akan bertambah saat dilakukan pembedahan. Penatalaksanaan nyeri dapat dilakukan dengan teknik non farmakologi salah satunya dengan terapi guided imagery. Tujuan penelitian untuk mengetahui pengaruh pemberian terapi guided imagery terhadap nyeri pada pasien post operasi fraktur di ruang Bougenvil RSUD dr. R Koesma Tuban.

Desain penelitian ini adalah Quasy Eksperimental dengan rancangan pretest-posttest with control group.Sampel diambil menggunakan systematic random sampling yang berjumlah 28 responden (14 responden kelompok eksperimen dan 14 responden kelompok kontrol).Pengumpulan data dilakukan dengan menggunakan lembar observasi.Analisa data penelitian menggunakan uji Mann Whitney.

Hasil uji Mann Whitney didapatkan hasil Asymp. Sig. (2-tailed) =0,000 dimana 0,000<0,05, maka $\mathrm{H}_{1}$ diterima $\mathrm{H}_{0}$ ditolak sehingga dapat disimpulkan bahwa terdapat pengaruh terapi guided imagery terhadap nyeri pada pasien post operasi fraktur.

Dapat disimpulkan bahwa terapi guided imagery mempunyai pengaruh terhadap nyeri pada pasien post operasi fraktur. Sehingga diharapkan terapi guided imagery dapat diterapkan oleh tenaga kesehatan khususnya tenaga perawat di rumah sakit sebagai terapi nonfarmakologi untuk mengurangi nyeri.
\end{abstract}

Kata kunci :Guided Imagery, Fraktur, Nyeri

ABSTRACT

Pain in patient's fracture will increase was conducted of the surgery. One of the ways to prevent the pain can do by non pharmacology's technique for example with guided imagery's therapy. The purpose of this research is to understand the effect of guided imagery's therapy that given to pain for post surgery fracture's patient in the Bougenvil's Room at the RSUD dr. R Koesma Tuban.

The design of this research is Quasy Experimental with pretest-posttest with control group's plan. The sample is taken by using systematic random sampling amount of 28 responden (14 of experiment group respondent and 14 of control group respondent). The collection of the data is using by the observation's sheet. The data analysis is using Mann Whitney's test.

The result of Man Whitney's test shows that Asymp. Sig's (2-tailed) =0,000 where 0,000<0,05, so the $H_{l}$ was accepted and the $H_{0}$ was rejected so it can be concluded that there is an effect of patient's pain on post surgery fracture.

So it can be concluded that guided imagery's therapy have an effect towards the Patient's pain on post Surgery Fracture. So the guided imagery's therapy can be implicated by the health staff for especially the nurse in the hospital as non pharmacology's therapy to reduce the pain.

Keywords: Guided Imagery, Fracture, Pain

\section{PENDAHULUAN}

Seorang yang mengalami patah tulang akan merasakan nyeri yang sangat hebat. Selain itu nyeri yang dirasakan pada pasien fraktur akan bertambah saat dilakukan tindakan pembedahan, sehingga menimbulkan adanya luka yang disengaja dan nyeri bertambah hebat. Nyeri setelah pembedahan normalnya dapat diramalkan hanya terjadi dalam durasi yang terbatas, lebih singkat dari waktu yang diperlukan 
untuk perbaikan alamiah jaringanjaringanyang rusak (Morison, 2004). Nyeri harus hilang segera setelah periode pasca operasi awal, setelah 3 sampai 4 hari (Smeltzer \& Bare, 2002). Namun nyeri pasca bedah pada pasien fraktur di ruang Bougenvil RSUD dr. R Koesma Tuban belum dapat diatasi denganbaik, dan pasien tetapmengalaminyerisehingga dapat mengganggu kenyamanan pasien. Hal ini dibuktikan bahwa masalah keperawatan utama pada pasien post operasi fraktur sampai dengan hari diperbolehkan pulang yaitu masih mengeluh nyeri (Buku Laporan Keperawatan Ruang Bougenvil, 2016).

Fraktur yang terjadi dapat menimbulkan gejala yang umum yaitunyeri atau rasa sakit. Survei kesehatan Nasional mencatat bahwa kasusfraktur pada tahun 2008 menunjukanbahwa prevalensi fraktur secara nasionalsekitar $27,7 \%$. Prevalensi ini khususnyapada lakilaki mengalami kenaikandibanding tahun 2009 dari 51,2\% menjadi54,5\%. Sedangkan pada perempuansedikit menurun yaitu sebanyak 2\% ditahun 2009, pada tahun 2010 menjadi1,2\% (Depkes RI,2010 dalam Djamal, 2015). Berdasarkan rekam medis di RSUD dr.R. Koesma Tuban jumlah pasien fraktur sepanjang tahun 2015 mencapai 883 orang, sedangkan pada 1 Januari sampai 31 Oktober 2016 mencapai 878 orang. Kasus fraktur merupakan kasus terbanyak dibanding dengan kasus yang lain. Berdasarkan anamnese dan pemeriksaan fisik pada pasien pasca operasi fraktur di ruang Bougenvil RSUD dr. R Koesma Tuban pada tanggal 16-22 November 2016 dari 10 orang $(100 \%)$ didapatkan hasil anamnese $100 \%$ mengeluh nyeri. Dengan ditunjang hasil pemeriksaan tekanan darah yang berkisar 130-160/80-100 $\mathrm{mmHg}$ yaitu6(60\%) orang, 110-125/60-90 $\mathrm{mmHg}$ yaitu $4(40 \%)$ orang. Hasil pemeriksaan nadi berkisar $90-100 x /$ menit yaitu $6(60 \%)$ orang, $60-80 \mathrm{x} /$ menit yaitu $4(40 \%)$ orang.

Nyeri setelah pembedahan merupakan hal yang fisiologis, tetapi hal ini merupakan salah satu keluhan yang paling ditakuti oleh klien setelah pembedahan.Rangsangan nyeri pada pembedahan ini disebabkan oleh rangsangan mekanik yaitu luka (insisi) dimana insisi ini akan merangsang mediator-mediator kimia dari nyeri seperti histamine, bradikinin, dan substansi prostaglandin dimana zat-zat ini dapat meningkatkan sensitifitas reseptor nyeri yang akan menimbulkan sensai nyeri (Smelzer \& Bare, 2001 dalam Nuraeni, 2015).

Metode untuk menutup gerbang nyeri dapat dilakukan berdasarkan teori Kolcaba (2003) bahwa kenyamanan dapat dicapai dengan 3 kategori intervensi yaitu intervensi kenyamanan standart, pelatihan/ coaching, dan tindakan menenangkan jiwa seperti pijatan, meditasi, relaksasi, terapi musik, sentuhan terapeutik, dan imajinasi terbimbing/ guided imagery. Sebagian besar pasien sering kali menganggap penanganan nyeri dengan pemberian obatobatan adalah satu-satunya pilihan terbaik. Namun terapi nonfarmakologis jika diterapkan juga sangat membantu dalam menghilangkn rasa nyeri, salah satunya adalah dengan menggunakan terapi guided imagery.

Teknik guided imagery dapat digunakan untuk mengurangi kecemasan, stress dan nyeri dengan menggunakan imajinasi seseorang yang melibatkan alat indera visual, sentuhan, pendengaran, pengecap dan penciuman, dengan tujuan pasien menjadi lebih tenang dan rileks. Selama latihan relaksasi seseorang dipandu untuk rileks dengan situasi yang tenang dan sunyi.Hal itu karena teknik imajinasi terbimbing dapat mengaktivasi sistem saraf parasimpatis (Potter \& Perry, 2006).

Tujuan penelitian ini adalah menganalisis pengaruh terapi guided imagery terhadap nyeri pada pasien post operasi fraktur di ruang Bougenvil RSUD dr. R Koesma Tuban. Manfaat penelitian ini diharapkan setelah mengetahui dan mempelajari terapi guided imagery dapat 
menjadi salah satu intervensi mandiri keperawatan dalam mengatasi nyeri pada pasien post operasi fraktur.

\section{BAHAN dan METODE}

Desain penelitian ini quasy eksperimental control group design. Kelompok intervensi diberikan perlakuan berupa terapi guided imagery, sedangkan kelompok kontrol tidak. Kedua kelompok diawali dengan pengukuran skala nyeri (pre tes), dan setelah diberikan perlakuan, kembali dilakukan pengukuran skala nyeri (post tes). Penelitian dilakukan di ruang Bougenvil RSUD dr. R Koesma Tuban. Waktu penelitian tanggal 23 Pebruari-23 Maret 2017. Populasi pada penelitian pasien post operasi fraktur. Teknik sampling yang digunakan pada penelitian ini adalah systematic random sampling berdasarkan kriteria inklusi dan ekslusi. Kriteria inklusi adalahpasien post operasi fraktur hari kedua, pasien post operasi closefracture, bersedia untuk menjadi responden, pasien post operasi fraktur dalam keadaan sadar, pasien post operasi fraktur yang tidak memiliki gangguan pendengaran, pasien post operasi fraktur dapat berkomunikasi dengan jelas. Sedangkan kriteria eksklusi pasien post operasi fraktur adalah pasien dengan keadaan gawat, pasien yang sudah diberi analgesik, pasien perempuan. Instrumen penelitian adalah SOP terapi guided imagery dan penilaian skala nyeri visual aid scale.

Pengumpulan data pada penelitian ini dimulai dengan ijin dari pihak institusi kemudian dilanjutkan ke pihak RSUD dr. $\mathrm{R}$ Koesma Tuban dan ruang Bougenvil. Setelah penelitian ini mendapat ijin dari pihak setempat maka peneliti melakukan pengumpulan data yaitumengambil data sekunder dari rekam medis RSUD dr. R Koesma Tuban dan data primer dengan melakukan observasi secara langsung terhadap tingkat nyeri pada pasien post operasi fraktur pada hari ke-2 setelah operasi. Observasi dilakukan sebelum (pretest) dan sesudah (posttest) terapi guided imagery.

Analisa data dalam penelitian ini yaitu analisa data bivariat yang menggunakan data yang berskala nominal dan ordinal (Pre-test Post-test intensitas nyeri). Penelitian ini akan dianalisis dengan teknik statistik yaitu dengan ujiMann Whitney. Uji dua sampel bebas Uji Mann Whitney pada statistik nonparametrik mempunyai tujuan yang sama dengan uji $t$ pada statistik parametrik, yakni ingin mengetahui apakah dua buah sampel yang bebas berasal dari populasi yang sama. 'Bebas' atau independen berarti dua sampel tersebut tidak tergantung satu dengan yang lain. (Santoso, 2010 dalam Faqih, 2012).

\section{HASIL}

\section{DATA UMUM}

Tabel 1 Distribusi Frekuensi Responden Berdasarkan Usia Pasien Post Operasi Fraktur di Ruang Bougenvil RSUD dr. R Koesma Tuban

\begin{tabular}{llll}
\hline No & Usia & $\boldsymbol{f}$ & \% \\
\hline 1 & $17-25$ & 12 & 42.9 \\
2 & $26-35$ & 9 & 32.1 \\
3 & $36-45$ & 1 & 3.6 \\
4 & $46-55$ & 6 & 21.4 \\
\hline & Jumlah & 28 & 100 \\
\hline
\end{tabular}

Sumber: Data Primer Peneliti, Tahun 2017

Berdasarkan tabel 1 dapat diketahui bahwa hampir setengahnya (42,9\%) responden berusia 17-25 tahun, hampir setengahnya $(32,1 \%)$ responden berusia 26-35 tahun, sebagian kecil (3,6\%) responden berusia 36-45 tahun, sebagian kecil $(21,4 \%)$ responden berusia $46-55$ tahun.

\section{DATA KHUSUS}

1) Tabel 2 Distribusi Frekuensi Responden Berdasarkan Nyeri pada Kelompok Eksperimen Sebelum Diberikan Intervensi Pasien Post Operasi Fraktur di Ruang Bougenvil RSUD dr. R Koesma Tuban

\begin{tabular}{cccc}
\hline No & Nyeri & $\boldsymbol{f}$ & $\boldsymbol{\%}$ \\
\hline 1 & Ringan & 0 & 0 \\
2 & Sedang & 14 & 100
\end{tabular}


Vol. 10 No. 2, Desember 2018

\begin{tabular}{cccc}
3 & Berat & 0 & 0 \\
\hline & Jumlah & 14 & 100 \\
\hline
\end{tabular}

Sumber: Data Primer Peneliti, Tahun 2017

Berdasarkan tabel 2 dapat diketahui bahwa dari 14 responden pada kelompok eksperimen sebelum diberikan intervensi seluruhnya $(100 \%)$ mengalami nyeri sedang.

2) Tabel 3 Distribusi Frekuensi Responden Berdasarkan Nyeri pada Kelompok Eksperimen Setelah diberikan Intervensi pada Pasien Post Operasi Fraktur di Ruang Bougenvil RSUD dr. R Koesma Tuban

\begin{tabular}{cccc}
\hline No & Nyeri & $\boldsymbol{f}$ & $\boldsymbol{\%}$ \\
\hline 1 & Menurun & 12 & 85,7 \\
2 & Menetap & 2 & 14,3 \\
3 & Meningkat & 0 & 0 \\
\hline & Jumlah & 14 & 100
\end{tabular}

Sumber: Data Primer Peneliti, Tahun 2017

Berdasarkan tabel 3 dapat diketahui bahwa dari 14 responden pada kelompok eksperimen setelah diberikan intervensihampir seluruhnya $(85,7 \%)$ responden mengalami penurunan nyeri, sedangkan sebagian kecil (14,3\%) responden tidak mengalami penurunan nyeri atau tetap.

3) Tabel 4 Distribusi Frekuensi Responden Berdasarkan Nyeri pada Kelompok Kontrol pada Pasien Post Operasi Fraktur di Ruang Bougenvil RSUD dr. R Koesma Tuban

\begin{tabular}{cccc}
\hline No & Nyeri & $\boldsymbol{f}$ & $\boldsymbol{\%}$ \\
\hline 1 & Ringan & 0 & 0 \\
2 & Sedang & 12 & 85.7 \\
3 & Berat & 2 & 14.3 \\
\hline & Jumlah & 14 & 100
\end{tabular}

Sumber: Data Primer Peneliti, Tahun 2017

Berdasarkan tabel 4 dapat diketahui bahwa dari 14 responden pada kelompok kontrol sebelum kelompok eksperimen mendapatkan intervensi hampir seluruhnya $(85.7 \%)$ mengalami nyeri sedang, sebagian kecil $(14.3 \%)$ mengalami nyeri berat.

4) Tabel 5 Distribusi Frekuensi Responden Berdasarkan Nyeri pada
Kelompok Kontrol Setelah 5 menit pada Pasien Post Operasi Fraktur di Ruang Bougenvil RSUD dr. R Koesma Tuban

\begin{tabular}{cccc}
\hline No & Nyeri & $\boldsymbol{f}$ & $\boldsymbol{\%}$ \\
\hline 1 & Menurun & 1 & 7,14 \\
2 & Menetap & 10 & 71,43 \\
3 & Meningkat & 3 & 21,43 \\
\hline & Jumlah & 14 & 100 \\
\hline
\end{tabular}

Sumber: Data Primer Peneliti, Tahun 2017

Berdasarkan tabel 5 dapat diketahui bahwa dari 14 responden yang tidak di berikan terapi guided imagery sebagian besar $(71,43 \%)$ responden tidak mengalami penurunan nyeri atau tetap, sebagian kecil responden mengalami penurunan nyeri sebesar $(7,14 \%)$ dan peningkatan nyeri sebesar $(21,43 \%)$.

5) Tabel Silang Pengaruh Terapi Guided Imagery terhadap Nyeri pada Pasien Post Operasi Fraktur di

\begin{tabular}{|c|c|c|c|c|}
\hline \multirow{2}{*}{$\begin{array}{c}\text { Terapi } \\
\text { Guided } \\
\text { Imagery }\end{array}$} & \multicolumn{3}{|c|}{ Nyeri Post Operasi Fraktur } & \multirow[b]{2}{*}{ Total } \\
\hline & $\begin{array}{c}\text { Menu- } \\
\text { run }\end{array}$ & Mene- tap & $\begin{array}{c}\text { Mening- } \\
\text { kat }\end{array}$ & \\
\hline $\begin{array}{l}\text { Kelompok } \\
\text { Eksperimen }\end{array}$ & $\begin{array}{c}12 \\
(85.7 \%)\end{array}$ & $2(14.3 \%)$ & $\begin{array}{c}0 \\
(0 \%)\end{array}$ & $\begin{array}{c}14 \\
(100 \%)\end{array}$ \\
\hline $\begin{array}{c}\text { Kelompok } \\
\text { Kontrol }\end{array}$ & $\begin{array}{c}1 \\
(7.14 \%)\end{array}$ & $\begin{array}{c}10 \\
(71.43 \%)\end{array}$ & $3(21.43 \%)$ & $\begin{array}{c}14 \\
(100 \%)\end{array}$ \\
\hline \multirow[t]{2}{*}{ Jumlah } & $\begin{array}{c}13 \\
(46.43 \%)\end{array}$ & $\begin{array}{c}12 \\
(42.86 \%)\end{array}$ & $3(10.71 \%)$ & $\begin{array}{c}28 \\
(100 \%)\end{array}$ \\
\hline & $\begin{array}{c}Z= \\
-4.057\end{array}$ & $\rho=0,000$ & $\begin{array}{c}\alpha= \\
0,05\end{array}$ & \\
\hline
\end{tabular}

Ruang Bougenvil RSUD dr. R

Koesma Tuban

Sumber: Data Primer Peneliti, Tahun 2017

Berdasarkan tabel silang dapat diketahui bahwa responden pada kelompok eksperimen hampir seluruhnya $(85,7 \%) \quad$ mengalami penurunannyerisedangkan responden pada kelompok kontrolsebagian kecil $(7,14 \%)$ mengalami penurunan nyeri, responden pada kelompok eksperimensebagian kecil $(14,3 \%)$ tidak mengalami penurunan nyeri atau tetap sedangkan responden pada kelompok kontrolhampir seluruhnya $(71,43 \%)$ tidak mengalami penurunan nyeri atau tetap, responden pada kelompok eksperimentidak satupun $(0 \%)$ mengalami peningkatan nyeri sedangkan responden 
pada kelompok kontrolsebangian kecil $(21,43 \%)$ mengalami peningkatan nyeri.

Uji Mann Whitney menggunakan SPSSdengan tingkat kemaknaan $\alpha=0,05$ diperoleh nilai Asymp. Sig. (2-tailed) $=$ 0,000 dimana $0,000<0,05$, maka $\mathrm{H}_{1}$ diterima $\mathrm{H}_{0}$ ditolak sehingga dapat disimpulkan bahwa terdapat pengaruh terapi guided imagery terhadap nyeri pada pasien post operasi fraktur.

\section{PEMBAHASAN}

1. Nyeri Post Operasi Fraktur pada Kelompok Eksperimen Sebelum Diberikan Intervensi

Hasil penelitian didapatkan responden pada kelompok intervensi saat pre test mempunyai skala nyeri rata-rata dari 4-7. Hal ini sesuai dengan penelitian yang dilakukan oleh Maria, dkk (2015) pada pasien post SC, dimana pengukuran skala nyeri pre test responden hasilnya sebagian besar mengalami nyeri dengan intensitas berkisar 5-7.

Beberapa faktor mungkin mempengaruhi terjadinya perbedaan skala nyeri pada kelompok eksperimen sebelum dan sesudah dilakukan intervensi diantaranya usia, lingkungan, ansietas dan koping individu. Dalam penelitian ini yang menjadi responden pada kelompok eksperimen sebagian besar berusia 17-25 tahun. Responden berada pada usia remaja akhir. Dalam teorinya Black dan Jane (2014) dalam Maria (2015) mengatakan bahwa usia dapat mengubah persepsi dan pengalaman nyeri. Menurut persepsi orang dewasa nyeri dapat berarti kelemahan, kegagalan atau kehilangan kontrol.Usia berkaitan dengan pengalaman dan kematangan jiwa, sehingga pada usia dewasa lebih cepat beradaptasi terhadap tingkat kecemasan, dimana kecemasan ini berbanding lurus dengan intensitas nyeri.

Faktor lingkungan, seperti fasilitas ruangan juga berbeda-beda, dimana di ruang kelas I dan II memiliki fasilitas dan tingkat kenyamanan yang lebih baik dibandingkan dengan ruang kelas III hal ini akan mempengaruhi respon nyeri yang dirasakan.

Faktor ansietas yang relevan atau berhubungan dengan nyeri dapat meningkatkan persepsi pasien terhadap nyeri. Ansietas yang tidak berhubungan dengan nyeri dapat mendistraksi pasien dan secara aktual dapat menurunkan persepsi nyeri. Secara umum, cara yang efektif untuk menghilangkan nyeri adalah dengan mengarahkan pengobatan nyeri ketimbang ansietas (Potter \& Perry, 2006).

Faktor koping individu Secara terusmenerus klien kehilangan kontrol dan tidak mampu untuk mengontrol lingkungan termasuk nyeri. Klien sering menemukan jalan untuk mengatasi efek nyeri baik fisik maupun psikologis. Penting untuk mengerti sumber koping individu selama nyeri. Sumber-sumber koping ini seperti berkomunikasi dengan keluarga, latihan dan bernyanyi dapat digunakan sebagai rencana untuk mensupport klien dan menurunkan nyeri klien (Potter \& Perry, 2006).

Berdasarkan penelitian dan teori yang ada pengukuran skala nyeri pada hari kedua cenderung dalam kategori sedang dikarenakan responden telah mendapatkan obat analgesik sehingga rasa nyeri yang dirasakan tidak sama dengan rasa nyeri hari pertama post operasi fraktur. Selain itu faktor usia pada kelompok eksperimen dalam masa remaja akhir. Pada remaja akhir mereka dapat mentoleransi rasa sakit yang dirasakan, pada faktor lingkungan yang sebagian besar menempati ruang kelas III dan II hal ini menyebabkan responden menjadi gelisah dan meningkatkan stress apabila rasa nyeri itu muncul. Beberapa responden mengaku bahwa dirinya kadang merasa cemas terhadap kondisi yang dialaminya sekarang, pikiran negatif akan menambah sensasi sakit yang dirasakan. Sehingga dapat dikatakan bahwa faktor kecemasan berpengaruh pada kelompok eksperimen sebelum dilakukan intervensi. Selain itu faktor koping individu pada saat dilakukan pre testhari kedua menunjukkan responden 
sudah mampu beradaptasi terhadap nyeri yang dirasakan.

2. Nyeri Post Operasi Fraktur pada Kelompok Eksperimen Setelah Diberikan Intervensi

Dari penelitian ini diketahui bahwa terdapat penurunan intensitas nyeri yang cukup berarti pada pasien post operasi fraktur yang diberikan terapi guided imagery. Terapi guided imagery merupakan salah satu penatalaksanaan nonfarmakologis yang mempunyai fungsi relaksasi dan merupakan penyembuh yang efektif untuk mengurangi nyeri(Snyder, 2006 dalam Hasim, 2015).

Guided Imagery/1majinasi positif dapat melemahkan psikoneuroimmunologi yang mempengaruhi respon stres, hal ini berkaitan dengan teori Gate Control yang menyatakan bahwa "hanya satu impuls yang dapat berjalan sampai sumsum tulang belakang ke otak pada satu waktu " dan " jika ini terisi dengan pikiran lain maka sensasi rasa sakit tidak dapat dikirim ke otak oleh karena itu rasa nyeri berkurang". Guided imagery juga dapat melepaskan endorphin yang merupakan substansi sejenis morfin yang disuplai oleh tubuh. Sehingga pada saat neuron nyeri perifer mengirimkan sinyal ke sinaps, terjadi sinapsis antara neuron nyeri perifer dan neuron yang menuju otak tempat seharusnya substansi $\mathrm{P}$ akan menghantarkan impuls. Pada saat tersebut, endorphin akan memblokir lepasnya substansi P dari neuron sensorik, sehingga transmisi impuls nyeri di medulla spinalis menjadi terhambat, sehingga sensasi nyeri pada pasien post operasi fraktur berkurang (Hart, 2008 dalam Hasim 2015).

$$
\text { Beberapa faktor mungkin }
$$
mempengaruhi terjadinya perbedaan skala nyeri pada kelompok eksperimen sebelum dan sesudah dilakukan intervensi diantaranya usia, lingkungan, ansietas dan koping individu. Dalam penelitian ini yang menjadi responden pada kelompok eksperimen sebagian besar berusia 17-25 tahun. Responden berada pada usia remaja akhir. Dalam teorinya Black dan Jane (2014) dalam Maria (2015) mengatakan bahwa usia dapat mengubah persepsi dan pengalaman nyeri. Menurut persepsi orang dewasa nyeri dapat berarti kelemahan, kegagalan atau kehilangan kontrol.Usia berkaitan dengan pengalaman dan kematangan jiwa, sehingga pada usia dewasa lebih cepat beradaptasi terhadap tingkat kecemasan, dimana kecemasan ini berbanding lurus dengan intensitas nyeri.

Faktor lingkungan, seperti fasilitas ruangan juga berbeda-beda, dimana di ruang kelas I dan II memiliki fasilitas dan tingkat kenyamanan yang lebih baik dibandingkan dengan ruang kelas III.Pada kelompok eksperimen sebagian besar menempati ruang kelas III dan II. Short (2003) dalam Falupi (2015) menjelaskan guided imagery dilakukan di ruangan yang tenang dan kondusif. Responden akan mudah berkonsentrasi terhadap apa yang disampaikan peneliti jika suasana nyaman.

Faktor ansietas yang relevan atau berhubungan dengan nyeri dapat meningkatkan persepsi pasien terhadap nyeri. Ansietas yang tidak berhubungan dengan nyeri dapat mendistraksi pasien dan secara aktual dapat menurunkan persepsi nyeri. Secara umum, cara yang efektif untuk menghilangkan nyeri adalah dengan mengarahkan pengobatan nyeri ketimbang ansietas (Potter \& Perry, 2006).

Faktor koping individu Secara terusmenerus klien kehilangan kontrol dan tidak mampu untuk mengontrol lingkungan termasuk nyeri. Klien sering menemukan jalan untuk mengatasi efek nyeri baik fisik maupun psikologis. Penting untuk mengerti sumber koping individu selama nyeri. Sumber-sumber koping ini seperti berkomunikasi dengan keluarga, latihan dan bernyanyi dapat digunakan sebagai rencana untuk mensupport klien dan menurunkan nyeri klien (Potter \& Perry, 2006).

Berdasarkan pada penelitian dan teori yang ada bahwa terapi guided imagery lebih efektif mempercepat penurunan nyeri. Dari 14 responden, 12 
responden mengalami penurunan nyeri, peneliti berpendapat bahwa responden yang mengalami penurunan nyeri karena disebabkan faktor usia pada masa remaja akhir lebih mudah untuk dapat mengikuti instruksi dan lebih kooperatif, sedangkan pada faktor lingkungan kondisi ruangan pada saat itu sedang kondusif sehingga terapi yang diberikan mudah diterima dan dapat berpengaruh, sedangkan pada faktor ansietas sebelum dan sesudah dilakukan intervensi terdapat perbedaan, setelah diberikan intervensi cemas yang dirasakan berkurang sehingga rasa sakit nyeri dapat menurun. Sedangkan terdapat 2 reponden yang mengalami nyeri menetap setelah diberikan intervensi hal ini dikarenakan faktor lingkungan pada saat itu kurang kondusif pada jam besuk pasien sehingga suasana bising akibatnya responden terganggu untuk berkonsentrasi dan mengikuti perintah. Selain itu responden juga kurang kooperatif dalam menjalani terapi.Kurang kooperatif responden disebabkan karena sikap acuh dan kurang pemahaman terhadap prosedur yang diberikan oleh peneliti.

\section{Nyeri Post Operasi Fraktur pada}

\section{Kelompok Kontrol}

Hasil penelitian menunjukkan nyeri saat pretest pada kelompok kontrol hampir seluruhnya mengalami nyeri sedang, sebagian kecil mengalami nyeri berat.

Responden kelompok kontrol memiliki skala nyeri yang tidak sama yaitu dari 4-7. Hal ini sesuai dengan teori yang diungkapkan Kozier et al(2010) yang menjelaskan nyeri merupakan sensasi yang tidak menyenangkan dan sangat individual dan tidak dapat dibagi dengan orang lain. Potter \& Perry (2006) juga menjelaskan bahwa tidak ada individu yang mengalami nyeri yang sama dan tidak ada dua kejadian nyeri yang sama menghasilkan respons atau perasaan yang identik pada seorang individu.

Beberapa faktor mungkin mempengaruhi terjadinya perbedaan skala nyeri pada kelompok kontrol sebelum dan sesudah dilakukan pengukuran skala nyeri diantaranya usia, lingkungan, ansietas dan koping individu. Dalam penelitian ini yang menjadi responden pada kelompok kontrol sebagian besar berusia 17-25 tahun dan 26-35 tahun. Responden berada pada usia remaja akhir dan dewasa awal. Dalam teorinya Black dan Jane (2014) dalam Maria (2015) mengatakan bahwa usia dapat mengubah persepsi dan pengalaman nyeri. Menurut persepsi orang dewasa nyeri dapat berarti kelemahan, kegagalan atau kehilangan kontrol.Usia berkaitan dengan pengalaman dan kematangan jiwa, sehingga pada usia dewasa lebih cepat beradaptasi terhadap tingkat kecemasan, dimana kecemasan ini berbanding lurus dengan intensitas nyeri.

Faktor lingkungan, seperti fasilitas ruangan juga berbeda-beda, dimana di ruang kelas I dan II memiliki fasilitas dan tingkat kenyamanan yang lebih baik dibandingkan dengan ruang kelas III.Pada kelompok kontrol sebagian besar menempati ruang kelas III. Ruangan yang bising dan kurang nyaman akan meningkatkan tingkat stres pasien sehingga akan meningkatkan rasa sakit yang dirasakan.

Faktor ansietas yang relevan atau berhubungan dengan nyeri dapat meningkatkan persepsi pasien terhadap nyeri. Ansietas yang tidak berhubungan dengan nyeri dapat mendistraksi pasien dan secara aktual dapat menurunkan persepsi nyeri. Secara umum, cara yang efektif untuk menghilangkan nyeri adalah dengan mengarahkan pengobatan nyeri ketimbang ansietas (Potter \& Perry, 2006).

Faktor koping individu Secara terusmenerus klien kehilangan kontrol dan tidak mampu untuk mengontrol lingkungan termasuk nyeri. Klien sering menemukan jalan untuk mengatasi efek nyeri baik fisik maupun psikologis. Penting untuk mengerti sumber koping individu selama nyeri. Sumber-sumber koping ini seperti berkomunikasi dengan keluarga, latihan dan bernyanyi dapat digunakan sebagai rencana untuk 
mensupport klien dan menurunkan nyeri klien (Potter \& Perry, 2006).

Berdasarkan penelitian dan teori yang ada pengukuran skala nyeri pada hari kedua cenderung dalam kategori nyeri sedang tetapi sebagian kecil masih dalam kategori nyeri berat. Selain itu faktor usia pada kelompok kontrol pre test dalam masa remaja akhir dan dewasa awal. Pada remaja akhir dan dewasa awal mereka dapat mentoleransi rasa sakit yang dirasakan, pada faktor lingkungan yang sebagian besar menempati ruang kelas III hal ini menyebabkan responden menjadi gelisah dan meningkatkan stress apabila rasa nyeri itu muncul. Beberapa responden mengaku bahwa dirinya kadang merasa cemas terhadap kondisi yang dialaminya sekarang, pikiran negatif akan menambah sensasi sakit yang dirasakan. Sehingga dapat dikatakan bahwa faktor kecemasan berpengaruh pada kelompok kontrol. Selain itu faktor koping individu pada saat dilakukan pre testhari kedua menunjukkan responden sudah mampu beradaptasi terhadap nyeri yang dirasakan.

4. Nyeri Post Operasi Fraktur pada Kelompok Kontrol Setelah 5 menit

Berdasarkan hasil penelitian yang dijelaskan pada tabel 5 dapat diketahui bahwa dari 14 responden yang tidak di berikan terapi guided imagery sebagian besar responden tidak mengalami penurunan nyeri atau tetap, sebagian kecil responden mengalami penurunan nyeri dan peningkatan nyeri.

Nyeri yang dirasakan akibat pembedahan pada setiap individu berbedabeda.Karena nyeri merupakan pengalaman subyektif yang hanya individu itu sendiri yang dapat menilainya.Pengukuran nyeri dengan pendekatan obyektif yang paling penting adalah menggunakan respon fisiologik tubuh terhadap nyeri itu sendiri (Tamsuri, 2007).

Berdasarkan penelitian dan teori yang ada tidak ada perbedaan yang signifikan terhadap skala nyeri pada kelompok kontrol sebelum dan sesudah 5 menit. Dari 14 responden terdapat 10 responden mengalami nyeri tetap dan 3 responden mengalami nyeri meningkat hal ini dipengaruhi oleh faktor lingkungan, mengingat sebagian besar responden menempati kelas 3 dimana tidak terdapat fasilitas seperti televisi dan kipas angin, selain itu satu ruangan terdapat banyak tempat tidur pasien sehingga menyebabkan suasana yang agak bising sehingga dapat mempengaruhi kenyamanan dan meningkatkan stress yang dapat menunjang tingkat nyeri pasien. Namun terdapat 1 responden yang mengalami penurunan nyeri dari berat ke sedang pada kelompok kontrol hal ini dikarenakan mekanisme koping pada responden tersebut baik, sumber koping ini seperti berkomunikasi dengan keluarga dan kebiasaan responden yang bermain gadget sehingga mengalihkan perhatian pada nyeri yang dirasakan.

5. Pengaruh Terapi Guided Imagery terhadap Nyeri pada Pasien Post Operasi Fraktur

Hasil analisa data yang digunakan pada penelitian ini adalah Uji Mann Whitney menggunakan SPSS dengan tingkat kemaknaan $\alpha=0,05$ diperoleh nilai Asymp. Sig. (2-tailed) $=0,000$ dimana $0,000<0,05$, maka $\mathrm{H}_{1}$ diterima $\mathrm{H}_{0}$ ditolak sehingga dapat disimpulkan bahwa terdapat pengaruh terapi guided imagery terhadap nyeri pada pasien post operasi fraktur.

Pada penelitian ini kelompok eksperimen diberikan perlakuan berupa terapi guided imagery sedangkan kelompok kontrol tidak. Penurunan skala nyeri tampak terjadi pada kelompok eksperimen. Beberapa faktor mungkin dominan mempengaruhi terjadinya perbedaan skala nyeri diantaranya usia dan lingkungan. Dalam penelitian ini yang menjadi responden kelompok eksperimen sebagian besar berusia 17-25 tahun Pada masa remaja akhir lebih mudah untuk dapat mengikuti instruksi dan lebih kooperatif. Sedangkan pada kelompok 
kontrol faktor usia pada dewasa awal berusia 26-35 tahun lebih mudah untuk mentoleransi rasa sakit yang dirasakan.

Faktor lingkungan, seperti fasilitas ruangan juga berbeda-beda mayoritas responden kelompok eksperimen berada diruang kelas III dan II sedangkan pada responden kelompok kontrol mayoritas berada diruang kelas III, dimana di ruang kelas I dan II memiliki fasilitas dan tingkat kenyamanan yang lebih baik dibanding dengan kelas III. Walaupun demikian pada saat melakukan terapi guided imagery di ruang kelas III, peneliti meminta bantuan fasilitator untuk membuat reponden dapat berkonsentrasi dan meminta perawat ruangan untuk meminta keluarga keluar ruangan hingga terapi selesai diberikan. Hal ini yang membuat skala nyeri antara responden di ruang kelas I dan II tidak ada perbedaan signifikan dengan kelas III. Maria (2015) menjelaskan guided imagery dilakukan di ruangan yang tenang dan kondusif di rumah sakit, akan tetapi ada beberapa keadaan yang dapat mengganggu dalam proses pelaksanaan guided imagery, seperti interupsi dari orang maupun staf dan suara-suara mengganggu lainnya.

Melalui guided imagery pasien akan terbantu untuk mengalihkan perhatian dari nyeri yang dirasakan dengan membayangkan hal-hal yang menyenangkan. Hal ini sehingga secara bertahap dapat menurunkan persepsi klien terhadap nyeri yang dirasakan.Didukung pendapat dari Ratnasari (2012) yang menyebutkan imagery therapist membimbing klien untuk merasakan atau visualisasi dengan tujuan relaksasi dan penyembuhan.Terapi ini sangat baik untuk manajemen sakit dan gejala fisik akibat masalah dan psikologis.

Keberhasilan terapi yang dilakukan disebabkan karena penerapan guided imagery berjalan baik dan dilakukan dengan petunjuk pelaksanaan terapi. Keberhasilan juga didukung oleh sikap kooperatif pasien yang mengikuti bimbingan peneliti dengan baik. Keberhasilan penerapan guided imagery memberikan dampak positif terhadap penurunan tingkat nyeri pada pasien post operasi fraktur.

Hasil penelitian ini juga didukung dari penelitian sebelumnya yang dilakukan oleh Andaryani (2013), tentang pengaruh teknik relaksasi guided imagery terhadap skala nyeri pada pasien fraktur femur di ruang bedah RSUP dr. Mohammad Hoesin Palembang tahun 2013, membuktikan adanya pengaruh relaksasi imajinasi terbimbing terhadap intensitas nyeri. Peneltian dari Nuraeni (2015) dengan hasil penelitian ada pengaruh teknik relaksasi (aromaterapi lavender) terhadap tingkat nyeri pada pasien post operasi fraktur di ruang Bougenvil dan Dahlia RSUD dr. R Koesma Tuban. Kesamaan hasil penelitian ini dengan penelitian sebelumnya memberikan gambaran efektivitas metode relaksasi-relaksasi dalam menurunkan intensitas nyeri.

Berdasarkan penelitian dan teori yang ada terapi guided imagery terbukti dapat mempengaruhi nyeri lebih cepat dibandingkan dengan hanya diberikan analgesik. Penurunan nyeri ini dapat membantu efek penyembuhan kondisi umum. Efek samping dari penggunaan analgesik juga dapat dikurangi karena terdapat pengaruh antara terapi guided imagery pada pasien post operasi fraktur sehingga direkomendasikan untuk penurunan dosis konsumsi analgesik.

Didukung dengan pendapat dari Tamsuri (2007) yang menyebutkan guided imagery merupakan teknik terapeutik yang digunakan untuk relaksasi atau tujuan proses penyembuhan sekaligus dapat menurunkan nyeri kronis.

\section{KESIMPULAN}

1. Nyeri pada pasien post operasi fraktur di ruang Bougenvil RSUD dr. R Koesma Tuban sebelum diberikan terapi guided imagery pada kelompok eksperimen dalam kategori nyeri. 
2. Nyeri pada pasien post operasi fraktur di ruang Bougenvil RSUD dr. R Koesma Tuban setelah diberikan terapi guided imagery hampir seluruhnya responden mengalami penurunan nyeri, sedangkan sebagian kecil responden tidak mengalami penurunan nyeri atau tetap.

3. Nyeri pada pasien post operasi fraktur di ruang Bougenvil RSUD dr. R Koesma Tuban pada kelompok kontrol sebelum kelompok eksperimen mendapatkan intervensi dalam kategori sedang sampai berat.

4. Nyeri pada pasien post operasi fraktur di ruang Bougenvil RSUD dr. R Koesma Tuban pada kelompok kontrol setelah kelompok eksperimen mendapatkan intervensisebagian besar responden tidak mengalami penurunan nyeri atau tetap, sebagian kecil responden mengalami penurunan nyeri.

5. Terdapat pengaruh pemberian guided imagery terhadap nyeri pada pasien post operasi fraktur di ruang Bougenvil RSUD dr. R Koesma Tuban. Ditunjukkan dengan hasil analisa data yang digunakan pada penelitian ini adalah Uji Mann Whitney dengan tingkat kemaknaan $\alpha=0,05$ diperoleh nilai Asymp. Sig. $(2$-tailed $)=0,000$ dimana $0,000<$ 0,05 , maka $\mathrm{H}_{1}$ diterima $\mathrm{H}_{0}$ ditolak sehingga dapat disimpulkan bahwa terdapat pengaruh terapi guided imagery terhadap nyeri pada pasien post operasi fraktur.

\section{SARAN}

1. Saran Teoritis

Diharapkan hasil penelitian ini dapat dipergunakan sebagai informasi ilmu pengetahuan khususnya ilmu keperawatan medical bedah dan metode riset yang berkaitan dengan nyeri.

2. SaranPraktis
1) Bagi institusi pendidikan agar terus dapat memperbanyak sumber bacaan baik buku, jurnal, maupun literature lainnya mengenai keperawatan khususnya yang berhubungan dengan penggunaan dan manfaat teknik guided imagery untuk dunia kesehatan.

2) Bagi perawat dan tenaga kesehatan dapat menerapkan terapi guided imagery sebagai terapi yang secara praktis untuk menurunkan nyerisehingga asuhan keperawatan yang lebih berkualitas dan pasien lebih puas terhadap pelayanan yang diberikan.

3) Bagi peneliti selanjutnya dapat membuat modifikasi manfaat terapi guided imagery yang tidak hanya digunakan untuk skala nyeri saja namun indikator lainnya seperti kecemasan, kualitas tidur, tekanan darah, stres maupun burnout situasi.Menempatkan responden pada satu ruangan yang sama sehingga diperoleh hasil yang lebih spesifik. Dan mengontrol pemberian analgesik sehingga hasil penelitian tidak bias.

\section{DAFTAR PUSTAKA}

Andarmoyo, S. 2016. Konsep Dan Proses Keperawatan Nyeri. Jogjakarta: Ar-Ruzz Media.

Andaryani, F \& Kardewi. 2013. Pengaruh Teknik Relaksasi Guided Imagery terhadap Skala Nyeri pada Pasien Fraktur Femur di Ruang Bedah RSUP Dr. Mohammad Hoesin Palembang, Jurnal Keperawatan Bina Husada, Volume 1, No. 2

Ani, C. H. A. 2014. Faktor-Faktor yang Mempengaruhi Intensitas Nyeri Pasien Pasca Bedah Abdomen di Rumah Sakit Umum Daerah $d r$. Pirngadi Medan. (online), 
(http://respiratory.unand.ac.id), diakses tanggal 04 Februari 2017

Dahlan, M. S. 2013. Statistik Untuk Kedokteran dan Kesehatan. Jakarta: Salemba Medika.

Digiulio, M., \& Jackson, D. 2014. Keperawatan Medikal Bedah. Yogyakarta: Rapha Publising.

Djamal R, Rompas S, Bawotong J. 2015. Pengaruh Terapi Musik Terhadap Skala Nyeri pada Pasien Fraktur di IRNA A RSUP Prof. DR. R.D. Kandou Manado, Vol. 3, No. 2, diakses 13 Desember 2016, (http://ejournal.unsrat.ac.id)

Faqih, M. U. 2012. Pengaruh Terapi Bermain terhadap Kecemasan AnakUsia 1-5 Tahun saat Hospitalisasi di Ruang Melati RSUD dr. R. Koesma Tuban. Skripsi tidak diterbitkan. Tuban : Program Studi S1 Keperawatan Sekolah Tinggi Ilmu Kesehatan Nahdlatul Ulama Tuban

Hartatik, Deni. 2016. Pengaruh Relaksasi Guided Imagery Terhadap Kualitas Tidur pada Lansia di Dsn Karang Gayam Ds. Banjarjo Kec. Bancar - Tuban. Skripsi tidak diterbitkan. Tuban : Program Studi S1 Keperawatan Sekolah Tinggi Ilmu Kesehatan Nahdlatul Ulama Tuban

Hasim,A. S. 2015. Guided Imagery(online),(http://ariasandyha sim.blogspot.co.id) diakses 13 Desember 2016

Helmi, Z. N. 2014. Buku Ajar Gangguan Muskuloskeletal . Jakarta: Salemba Medika.

Hidayat, A. A. 2007. Riset Keperawatan dan Tehnik Penulisan Ilmiah. Jakarta: Salemba Medika.
Hidayat, A. A. 2008. Pengantar Konsep Dasar Keperawatan. Jakarta: Salemba Medika.

Maria, dkk. 2015. Pengaruh Terapi Guided Imagery and Music (GIM) terhadap Skala Nyeri Luka Pasien Post Operasi Sectio Caesarea (SC) di RSUD Ende. Vol. 4, No. 3, diakses 13 Desember 2016, (http://ejournal.unsrat.ac.id)

Morison, M. J. 2004. Manajemen Luka. Jakarta: EGC.

Muttaqin, A. 2008. Buku Ajar Asuhan Keperawatan Klien dengan Gangguan Sistem Persarafan. Jakarta: Salemba Medika.

Muttaqin, A., \& Sari, K. 2009. Asuhan Keperawatan Perioperatif Konsep, Proses, dan Aplikasi. Jakarta: Salemba Medika.

Ningsih, N., \& Lukman. 2009. Asuhan Keperawatan Klien dengan Gangguan Sistem Musculoskeletal. Jakarta: Salemba Medika.

Nuraeni, Dewi. 2015. Pengaruh Aromaterapi Lavender (Lavandula Angustifolia) terhadap Nyeri Post Operasi Fraktur di Ruang Bougenfil dan Dahlia RSUD Dr. R Koesma Tuban. Skripsi tidak diterbitkan. Tuban : Program Studi S1 Keperawatan Sekolah Tinggi Ilmu Kesehatan Nahdlatul Ulama Tuban

Nursalam. 2016. Metodologi Penelitian Ilmu Keperawatan Pendekatan Praktis Edisi 4. Jakarta: Salemba Medika.

Potter, \& Perry. 2006. Fundamental Keperawatan Konsep, Proses, dan Praktik Edisi 4. Jakarta: EGC.

Price, S. A., \& Wilson, L. M. 2006. Patofisiologi Konsep Klinis 
Vol. 10 No. 2, Desember 2018

Proses-Proses Penyakit Edisi 6. Jakarta: EGC.

Sjamsuhidajat, \& Jong, W. d. 2005. Buku Ajar Ilmu Bedah, Edisi II. Jakarta: EGC.

Smeltzer, S. C., \& Bare, B. G. 2002. Buku Ajar Keperawatan Bedah Edisi 8 Vol 1. Jakarta: EGC.
Smeltzer, S. C., \& Bare, B. G. 2002. Buku Ajar Keperawatan Medikal Bedah Edisi 8 Vol. 3. Jakarta: EGC.

Suza, D. E. 2007. Konsep \& Penatalaksanaan Nyeri. Jakarta: EGC.

Tamsuri, A. 2007. Konsep dan Penatalaksanaan Nyeri. Jakarta: EGC. 